\title{
Faculty development in medical education: an environmental scan in countries within the Asia pacific region
}

\author{
Dujeepa D. Samarasekera', Shuh Shing Lee ${ }^{1}$, Ardi Findyartini ${ }^{2}$, Rita Mustika ${ }^{2}$, Hiroshi Nishigori ${ }^{3}$,
} Shunsuke Kimura ${ }^{4}$ and Young-Mee Lee

${ }^{1}$ Centre for Medical Education, Yong Loo Lin School of Medicine, National University of Singapore, Singapore, ${ }^{2}$ Department of Medical Education, Faculty of Medicine, Universitas Indonesia, Jakarta, Indonesia, ${ }^{3}$ Center for Medical Education, Graduate School of Medicine, Nagoya University, Nagoya, ${ }^{4}$ Medical Education Center, Kyoto University, Kyoto, Japan, and ${ }^{5}$ Department of Medical Education, Korea University College of Medicine, Seoul, Korea

Purpose: In recent years, faculty development (FD) research is more noticeable within an inter-professional context and in allied health education. However, there is a paucity of published literature on FD medical education programs in Asia. With the formation of the Asia Pacific Medical Education Network (APME-Net) in 2015, a scoping review of an environmental scan of FD medical education programs in main institutions in South East Asia and Australia in 2018 was conducted.

Methods: A survey was developed to collect data on FD in medical education after several rounds of discussion with APME-Net members. The representatives from nine countries in Asia and Australia were invited to partner in this research project. They sent the questionnaire to the Dean of all different medical schools after ethical clearance. The data collected was analyzed using descriptive statistics.

Results: Only institutions in four countries responded to the questionnaire. The medical/health professions education center/ department/unit has been established in most educational institutions in these countries. These centers/departments/units mostly carry out FD programs to improve the teaching and learning skills of trained participants, particularly clinical teachers via workshops and seminars. Staffing issues and participant buy-in are the current key priorities of the center/department/unit in terms of FD. Lastly, research related FD program has not been well-supported in these countries, hence, the lack of publication in this area.

Conclusion: Collaboration between countries to address key areas of interest and develop more standardized and productive FD medical education is required especially in research.

Key Words: Medical education, Teacher training, Staff development, Multicenter study

\section{Introduction}

Systematic and structured faculty development (FD) was developed due to the need of training in educational theory and teaching methodologies among teachers involved in Health Professions Education programs. The previous assumption was that the teachers involved in Health Professions Education programs are capable of teaching once they specialized in their subject areas and joined an institution. It was assumed, during the old days, health professions educators were capable of
Received: April 22, 2020 • Revised: May 5, 2020 • Accepted: May 6, 2020

Corresponding Author: Dujeeepa D. Samarasekera (https://orcid.org/0000-0002-6916-6741) Centre for Medical Education, Yong Loo Lin School of Medicine, National University of Singapore, Block MD 11, \#05-10, Clinical Research Centre, 10 Medical Drive, Singapore, 117597 Tel: +65.6516.3760 Fax: +65.6872.1454 email: dujeepa@nus.edu.sg
Korean J Med Educ 2020 Jun; 32(2): 119-130.

https://doi.org/10.3946/kjme.2020.160

eISSN: 2005-7288

(C) The Korean Society of Medical Education. All rights reserved. This is an open-access article distributed under the terms of the Creative Commons Attribution Non-Commercial License (http:// creativecommons.org/licenses/by-nc/3.0/), which permits unrestricted non-commercial use, distribution, and reproduction in any medium, provided the original work is properly cited. 
teaching once they joined an institution. However, it was soon apparent that some training will assist them to teach more effectively and enhance student learning. Since then, FD has been incorporated as an essential feature of medical school organization and gained attention in different parts of the world.

Multiple definitions of FD have been put forward by different researchers. However, these definitions share two key perspectives: consists of a broad range of activities and prepares faculty in their roles in terms of knowledge, skills, and behavior [1-4]. However, a faculty member's roles have become more complex to meet the ever changing demands of education. Apart from being an educator, faculty member is also a leader, a researcher, and a scholar [4]. Their roles and identities change when the career progresses from a junior member stage (such as becoming a program director or dean). Hence, the FD should also be strategically developing to enhance teachers' identity [5].

FD has become an essential feature of Health Professions Education programs and research related to this area is also growing. There are multiple systematic reviews published since 1977 in medical education [6]. In general, research articles were largely focusing on evaluating the intervention for FD by exploring participant perceptions and learning impact [6,7]. There are also reviews regarding the formats used for FD such as standalone workshops, longitudinal and mixed formats [8-10]. In recent years, FD research is more noticeable within an inter-professional context and in allied health education [11-13]. However, there is a paucity of published literature on FD medical education programs in Asia. Only four studies in Asia were published on the FD programs in general education according to a systematic review conducted by Phuong et al. [10] recently.

With the formation of the Asia Pacific Medical
Education Network (APME-Net) in 2015, a scoping review of an environmental scan of FD medical education programs in main institutions in South East Asia and Australia in 2018 was conducted. The information collected will be useful to identify areas to collaborate and provide support to institutions, as well as to better understand the different emphasis of FD for each country.

\section{Methods}

\section{Methodology}

A survey was developed to collect data on FD in medical education. At the initial stage, literature review was carried out to look for existing questionnaires. After several rounds of discussion with APME-Net members, it was decided to develop a questionnaire since limited contextually relevant resources were found. Key domains were identified by the group and relevant questions were formulated. After several rounds of refinement within the group, a final set of questions were identified. To develop a questionnaire, a few domains were discussed and formed among the members of APME-Net. These domains are approaches to FD, implementation and evaluation of FD program, and research in FD. Each member contributes a few questions pertaining to the domains. Once the questions were finalized, the entire questionnaire was circulated to 12 representatives, one from each country, to scrutinize and refine further the items. The finalized questionnaire in English was vetted by a committee which comprised of experts in FD.

The representatives from nine countries in Asia and Australia were invited to partner in this research project. Representative from each country was required to adhere to their Ethical Review Board protocol. Indonesia and 
Korea required translation of the questionnaire to their first language before administering. The representatives sent the questionnaire to the dean of all different medical schools after Institutional Review Board (IRB) clearance for their concurrence and actions. The involvement of different schools in filling up the questionnaire is voluntary. The questionnaire was filled by the medical education department/unit/center of the schools with approval from the dean of the school. The data collected was analyzed using descriptive statistics.

\section{Ethical review}

Ethical approval for Singapore was obtained from the IRB at National University of Singapore (reference no., S-17-135E), ethical approval for South Korea was approved from the IRB at Korea University (approval no., 1040548-KU-IRB-17-198-A-1) while ethical approval for Indonesia was obtained from IRB at Faculty of Medicine Universitas Indonesia (letter no., 1187/ UN2.F1/ETIK/11/2017). Since the survey responses are anonymized and the main IRB was approved by the National University of Singapore, it has been exempted by the IRB in Japan.

\section{Results}

Table 1 provides a brief overview of the medical schools of each country involved in this project. Most medical schools in the country belong to government institutions except Indonesia which has larger portion of private medical schools than government. All medical schools in the respective countries have a medical/health professions education center/department/unit; however, the number of full-time academic staff in the center/ department/unit is limited. Most of the medical schools in the respective countries still rely on part time academic staff.

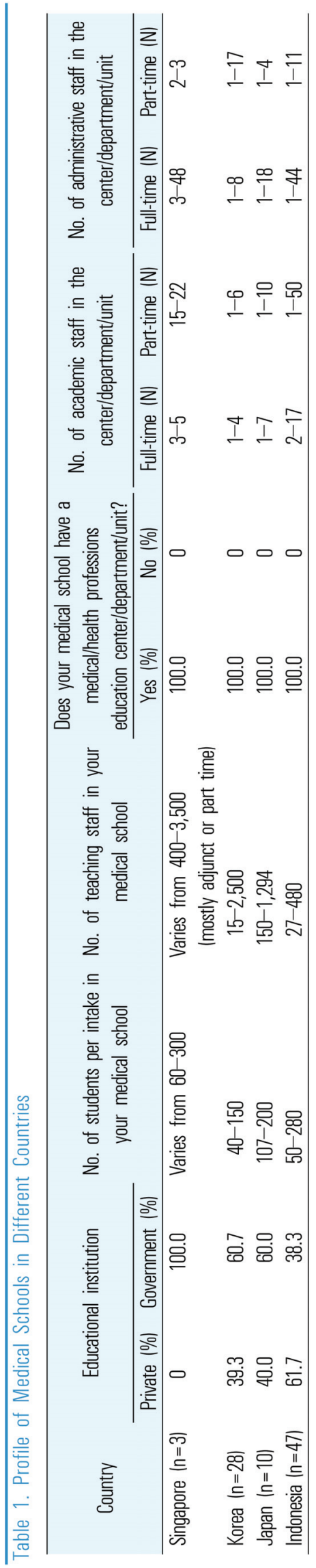


Table 2. The Functions of the Center/Department/Unit as well as the Training Portfolio

\begin{tabular}{|c|c|c|c|c|}
\hline \multirow{2}{*}{ Question } & \multicolumn{4}{|c|}{ Country } \\
\hline & Singapore $(\%)$ & Korea $|\%|$ & Japan $(\%)$ & Indonesia $(\%)$ \\
\hline \multicolumn{5}{|l|}{ Does the center/department/unit in your institution carry out FD programs? } \\
\hline Yes & 100.0 & 96.4 & 90.0 & 87.2 \\
\hline No & 0 & 3.6 & 10.0 & 12.8 \\
\hline \multicolumn{5}{|l|}{$\begin{array}{l}\text { The function(s) of the medical/health professions education center/department/unit other } \\
\text { than carrying out FD programs? (You may choose more than one) }\end{array}$} \\
\hline Curriculum planning and design & 67.0 & 92.9 & 90.0 & 80.9 \\
\hline Course evaluation & 100.0 & 89.3 & 70.0 & 26.0 \\
\hline Research & 100.0 & 89.3 & 30.0 & 10.6 \\
\hline Run the medical programs & 67.0 & 42.9 & 80.0 & 4.3 \\
\hline \multicolumn{5}{|l|}{$\begin{array}{l}\text { The purpose/s)/intent of carrying out the FD programs offered by the center/department/unit } \\
\text { in your institution? (You may choose more than one) }\end{array}$} \\
\hline To improve teaching and learning skills (include curriculum design, delivery, and assessment) & 66.7 & 100.0 & 90.0 & 97.9 \\
\hline For leadership and management skills development & 66.7 & 25.0 & 30.0 & 19.1 \\
\hline For research capacity building & 66.7 & 21.40 & 30.0 & 14.9 \\
\hline For academic and career development & 66.7 & 32.1 & 20.0 & 29.8 \\
\hline For organizational change & 33.3 & 21.4 & 70.0 & 12.8 \\
\hline \multicolumn{5}{|l|}{$\begin{array}{l}\text { Type of students (educational level) do the trained participants teach? (You may choose } \\
\text { more than one) }\end{array}$} \\
\hline Undergraduate students & 66.7 & 100.0 & 100.0 & 97.9 \\
\hline Postgraduate students & 66.7 & 53.6 & 40.0 & 17.0 \\
\hline Other (Please specify) & Nil & Nil & Nil & $\begin{array}{l}\text { Doctors \& } \\
\text { professionals }\end{array}$ \\
\hline \multicolumn{5}{|l|}{$\begin{array}{l}\text { Which groupls) of participants does the center/department/unit in your institution conduct } \\
\text { training for? (You may choose more than one) }\end{array}$} \\
\hline Uni-professional & 66.7 & 96.4 & 80.0 & 80.9 \\
\hline Multi-professional & 66.7 & 3.6 & 50.0 & 38.3 \\
\hline Inter-professional & 66.7 & 17.9 & 50.0 & 12.8 \\
\hline Other (Please specify) & Nil & Nil & Nil & Nil \\
\hline \multicolumn{5}{|l|}{$\begin{array}{l}\text { What type of staff does the center/department/unit train? (You may choose more than } \\
\text { one) }\end{array}$} \\
\hline New staff & 66.7 & 85.7 & 70.0 & 93.6 \\
\hline Biomedical science teachers & 33.3 & 25.0 & 60.0 & 66.0 \\
\hline Curriculum committee members & 66.7 & 75.0 & 30.0 & 44.7 \\
\hline Course conveners & 66.7 & 82.1 & 70.0 & 80.9 \\
\hline Medical educationalists & 66.7 & 17.9 & 40.0 & 2.1 \\
\hline Clinical teachers & 66.7 & 82.1 & 90.0 & 91.5 \\
\hline Educational leaders & 66.7 & 3.6 & 70.0 & 4.3 \\
\hline Clinicians/practitioners & 66.7 & 10.7 & 70.0 & 55.3 \\
\hline Education-related administrative staff & 33.3 & 7.1 & 40.0 & 14.9 \\
\hline Sessional/part-time staff & 33.3 & 0 & 20.0 & 19.1 \\
\hline Public health teachers & 0 & 0 & 40.0 & 51.0 \\
\hline Support staff (laboratory staff, technicians) & 0 & 0 & 10.0 & 12.8 \\
\hline
\end{tabular}

FD: Faculty development.

Table 2 illustrates the functions of the center/ department/unit as well as the training portfolio. The main purpose of the establishment of the medical education center/department/unit is still to carry out FD. However, not all medical education centers/departments/ units in certain countries carry out FD programs. For example, it is the Education Committee that conducts FD program in one of the schools in Japan and some schools in Indonesia cooperate with human resource unit and faculty leaders to carry out FD program. Other than FD, medical education center/department/unit also involved in curriculum planning and design, particularly in 
Indonesia. Most medical education center/department/ unit do not run medical program except Japan (80\% of the centers). The intent of carrying FD programs is still focusing on improving teaching and learning skills (include curriculum design, delivery, and assessment).
There is still a lack of emphasis on building research capacity, leadership and management skills, and career development. The target being trained are very much in isolation which is uni-professional rather than multi or inter-professionals. Increasingly, clinical teachers are

Table 3. Approaches for FD Program

\begin{tabular}{|c|c|c|c|c|}
\hline \multirow{2}{*}{ Question } & \multicolumn{4}{|c|}{ Country } \\
\hline & Singapore & Korea & Japan & Indonesia \\
\hline \multicolumn{5}{|c|}{$\begin{array}{l}\text { Which of the following approaches are used by the center/department/unit for FD programs in } \\
\text { your institution? (You may choose more than one) }\end{array}$} \\
\hline Workshops & 100.0 & 96.4 & 100.0 & 91.5 \\
\hline Seminars or short courses & 66.7 & 82.1 & 100.0 & 95.7 \\
\hline Online learning & 66.7 & 14.3 & 40.0 & 8.5 \\
\hline Directed self-learning & 66.7 & 0 & 10.0 & 12.8 \\
\hline Formal diploma/degree/master program (ME/MHPE) & 33.3 & 7.1 & 10.0 & 14.9 \\
\hline Peer learning & 33.3 & 7.1 & 10.0 & 46.8 \\
\hline Communities of practice & 33.3 & 0 & 10.0 & 12.8 \\
\hline Fellowship and/or other longitudinal programs & 33.3 & 0 & 10.0 & 8.5 \\
\hline On-the-job training & 66.7 & 0 & 0 & 17.0 \\
\hline \multicolumn{5}{|c|}{$\begin{array}{l}\text { Which formatts) does the medical/health professions education center/department/unit in your institution } \\
\text { use to carry out online FD development? (You may choose more than one) }\end{array}$} \\
\hline Manual or guidelines & 100.0 & 53.6 & 0 & 38.3 \\
\hline Massive open online courses & 0 & 14.3 & 10.0 & 0 \\
\hline Forum (Padlet) & 0 & 0 & 10.0 & 6.4 \\
\hline Blog & 0 & 17.9 & 0 & 0 \\
\hline Learning management system & 66.7 & 3.6 & 50.0 & 0 \\
\hline \multicolumn{5}{|c|}{ How frequently (number) is/are the faculty development programapproach(es) used (per year)? } \\
\hline Workshops & $65(70.0)$ & $146(38.0)$ & $33(57.0)$ & $109(42.0)$ \\
\hline Seminar & $22(24.0)$ & $196(51.0)$ & $13(22.0)$ & $106(41.0)$ \\
\hline Online learning & $3(3.0)$ & $39(10.0)$ & $8(14.0)$ & $8(3.0)$ \\
\hline Fellowship & $1(1.0)$ & 0 & $3(5.0)$ & $12(5.0)$ \\
\hline Formal degree/master program & $2(2.0)$ & 0 & $1(2.0)$ & $22(9.0)$ \\
\hline Other (Please specify) & Nil & Nil & Nil & $\begin{array}{l}\text { Peer learning } \\
(1-2)\end{array}$ \\
\hline \multicolumn{5}{|c|}{$\begin{array}{l}\text { How frequently (estimated number) are the following topics addressed (per year) in the FD program(s) } \\
\text { carried out by the medical/health professions education center/department/unit in your institution? }\end{array}$} \\
\hline Teaching and learning & $16(29.0)$ & $73(42.0)$ & $17(31.0)$ & 132 (38.0) \\
\hline Assessment methods & $14(25.0)$ & $40(23.0)$ & $13(24.0)$ & $88(25.0)$ \\
\hline Accreditation and quality assurance & $2(4.0)$ & $29(17.0)$ & $5.5(10.0)$ & $50(14.0)$ \\
\hline Program evaluation & $2(4.0)$ & $17(10.0)$ & $8(15.0)$ & $56(16.0)$ \\
\hline Leadership and management & $11(20.0)$ & $8(5.0)$ & $6.5(12.0)$ & $14(4.0)$ \\
\hline Scholarship of teaching and learning & $11(20.0)$ & $8(5.0)$ & $4(7.0)$ & $11(3.0)$ \\
\hline \multicolumn{5}{|c|}{$\begin{array}{l}\text { How does the medical/health professions education center/department/unit in your institution incentivize } \\
\text { participants to attend the } F D \text { programs? (You may choose more than one) }\end{array}$} \\
\hline Full/partial funding & 100.0 & 46.4 & 40.0 & 38.3 \\
\hline Mandatory as part of job requirement & 66.7 & 50.0 & 20.0 & 38.3 \\
\hline Credit points for promotion & 33.3 & 71.4 & 50.0 & 10.6 \\
\hline Credit points for tenure & 33.3 & 14.3 & 0 & 0 \\
\hline
\end{tabular}

Data are presented as $\%$ or number $(\%)$.

FD: Faculty development.

${ }^{a}$ IIndicates Medical Education \& Master of Health Professions Education. 
being trained ( $>60 \%$ for each countries) as compared to biomedical science teachers. In fact, Singapore and Korea has a lower percentage in training the biomedical science teachers. Education-related administrative staff are more well-trained in Japan and Singapore while Indonesia trained $>50 \%$ of the public health teachers.

In terms of approaches, a workshop is still the preferred method, followed by seminar or short courses as compared to others (Table 3). This is aligned with the frequency of the use of the approaches (question 16). With the advancement of technology, online learning appeared not as popular as other methods. Even if online learning is utilized, most of the time it is to disseminate guidelines or manual. The topics addressed during FD program is still teaching and learning as well as assessment, not much weight has been given to scholarship of teaching and learning and leadership $(<20 \%)$.

Table 4 shows the implementation and evaluation of FD program. Majority of the medical schools in the respective countries conduct a need analysis to identify

Table 4. Implementation and Evaluation of FD Program

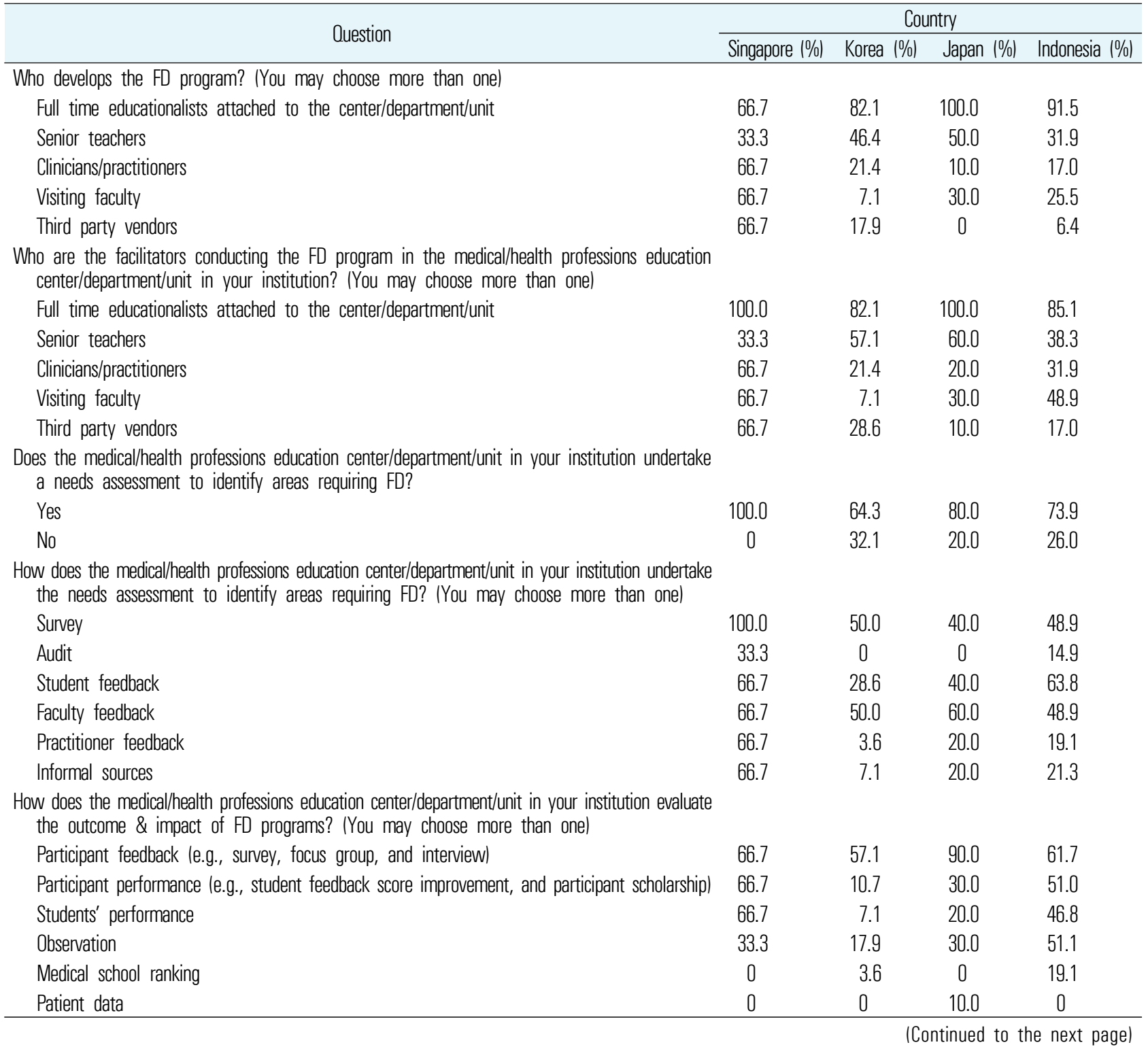




\begin{tabular}{|c|c|c|c|c|}
\hline \multirow{2}{*}{ Question } & \multicolumn{4}{|c|}{ Country } \\
\hline & $\begin{array}{l}\text { Singapore }(\%) \\
\end{array}$ & Korea $(\%)$ & Japan (\%) & Indonesia (\%) \\
\hline \multicolumn{5}{|c|}{$\begin{array}{l}\text { What is/are the support system(s) available for the medical/health professions education center/ } \\
\text { department/unit in your institution to conduct FD programs? (You may choose more than one) }\end{array}$} \\
\hline Internal funding & 100.0 & 71.4 & 70.0 & 85.1 \\
\hline External funding & 66.7 & 3.6 & 10.0 & 12.8 \\
\hline Support staff & 66.7 & 32.1 & 60.0 & 70.2 \\
\hline Rooms/venues to conduct FD programs & 66.7 & 78.6 & 30.0 & 72.3 \\
\hline IT facilities & 33.3 & 25.0 & 30.0 & 57.4 \\
\hline National policy & 0 & 10.7 & 0 & 21.3 \\
\hline \multicolumn{5}{|c|}{$\begin{array}{l}\text { What are the challenges \& limitations faced in operationalizinga FD program? (You may choose } \\
\text { more than one) }\end{array}$} \\
\hline Lack of support staff & 66.7 & 60.7 & 60.0 & 57.4 \\
\hline Lack of support systems & 66.7 & 35.7 & 60.0 & 38.3 \\
\hline Lack of funding & 33.3 & 35.7 & 10.0 & 40.4 \\
\hline Lack of facilitators & 66.7 & 78.6 & 50.0 & 27.7 \\
\hline Resistance from staff & 33.3 & 28.6 & 20.0 & 39.6 \\
\hline Lack of incentives & 66.7 & 46.4 & 70.0 & 38.3 \\
\hline Competing interests (e.g., research and/or practice obligations, and so forth) & 66.7 & 82.1 & 30.0 & 70.2 \\
\hline \multicolumn{5}{|c|}{$\begin{array}{l}\text { What is/are the current prioritylies) of the medical/health professions education center/department/unit } \\
\text { in your institution in terms of faculty development? (You may choose more than one) }\end{array}$} \\
\hline Staffing-expertise or support staff & 66.7 & 64.3 & 90.0 & 59.6 \\
\hline Participant buy-in & 66.7 & 67.9 & 10.0 & 74.5 \\
\hline Infrastructure strengthening & 66.7 & 46.3 & 40.0 & 34.0 \\
\hline International collaboration & 33.3 & 0 & 20.0 & 19.1 \\
\hline Development and implementation of postgraduate program(s) in medical education & 66.7 & 0 & 30.0 & 8.5 \\
\hline Other (Please specify) & Nil & Nil & Nil & $\begin{array}{l}\text { Support from } \\
\text { the faculty }\end{array}$ \\
\hline
\end{tabular}

FD: Faculty development.

areas required for FD. Other than survey, student \& faculty feedback are the most commonly used method to undertake a need assessment. None of the schools in Japan or Korea use audit as a source of need assessment. In respect of the FD developers and facilitators, this task falls under full-time educationalists attached to the center/department/unit. The involvement of senior teachers is also prevalent in teaching the faculty members. Most schools in the four countries are predominantly supported by internal funding $(>70 \%)$; therefore, lack of funding is not a challenge in these countries. From the data, we also noticed that the information technology (IT) facilities are not so well-supported in Singapore, Japan, and Korea as compared to Indonesia. As for challenges, the data is quite equally distributed for Singapore. The least limitation for Singapore and South Korea is funding and resistance from the staff. However, South Korea is heavily lack of facilitators and competing interests with other areas such as research, which is one of the biggest challenges for Indonesia. Japan, on the other hand, lacks of incentives to incentivize the faculty member to attend FD program and support staff. Therefore, $90 \%$ of the schools in Japan felt that staffing is their priority issue to be resolved as compared to other countries which have chosen participant buy-in as their priority.

Table 5 indicated the last part of the survey which is the research in FD. Apart from Singapore which carries out any research related to $\mathrm{FD}$, less than $50 \%$ of the medical schools in Indonesia carry out research pertaining 


\begin{tabular}{|c|c|c|c|c|}
\hline \multirow{2}{*}{ Question } & \multicolumn{4}{|c|}{ Country } \\
\hline & Singapore $(\%)$ & Korea $(\%)$ & Japan $(\%)$ & Indonesia $(\%)$ \\
\hline \multicolumn{5}{|c|}{$\begin{array}{l}\text { Does the medical/health professions education center/department/unit in your institution carry out } \\
\text { any research related to FD? }\end{array}$} \\
\hline Yes & 100.0 & 17.9 & 20.0 & 46.8 \\
\hline No & 0 & 82.1 & 80.0 & 51.0 \\
\hline \multicolumn{5}{|c|}{ The focus of the FD-related research is/are: (You many choose more than one) } \\
\hline Evaluation of intervention in $\mathrm{FD}$ program & 66.7 & 3.6 & 20.0 & 26.0 \\
\hline Systematic review of FD & 0 & 14.3 & 0 & 6.4 \\
\hline Impact of FD program on teachers & 66.7 & 7.1 & 20.0 & 23.4 \\
\hline Impact of FD program on students & 33.3 & 10.7 & 10.0 & 36.2 \\
\hline Challenges in FD program & 33.3 & 7.1 & 0 & 17.0 \\
\hline Other (Please specify) & Nil & $\mathrm{Nil}$ & Nil & Nil \\
\hline \multicolumn{5}{|c|}{ Has your institution published any paper(s) related to research in FD? } \\
\hline Yes & 33.3 & 0 & 0 & 4.2 \\
\hline No & 66.7 & 100.0 & 100.0 & 95.8 \\
\hline
\end{tabular}

FD: Faculty development.

to this area and it is even lower for Korea and Japan. Most of the research conducted is still focusing on evaluation of intervention in FD program and its impact. Due to limited involvement in FD research, the publication produced is also scarce (which is less than 30\%).

\section{Discussion}

FD program in Asia Pacific, being one of the world's most dynamic regions, is significantly drawing huge attention due to the high demand and extensive changes in medical education. This is because FD has a significant impact on knowledge, skills, and behaviors as teachers and educators, leaders and managers, and researchers and scholars. As there are not many researches has been carried out in these regions, Singapore, Korea, Japan, and Indonesia are the countries which are involved in this environmental scan to provide a better understanding of the progression of $\mathrm{FD}$.

From the data, we noticed that Indonesia has a higher percentage of private medical institutions as compared to the other countries. Given the aim to improve the ratio of medical doctor and total population across regions in Indonesia, the number of quality medical doctors is contributed by both public and private medical schools. Current regulation in Indonesia also allows the establishment of private medical schools so long as the schools fulfil and maintain the expected standards. Most of the medical/health professions education center/ department/unit still rely on the support of part time academic staff with a few full timers. With FD becoming more and more important, all medical institutions consist of a medical/health professions education center/ department/unit in these countries.

Majority of the medical/health professions education center/department/unit in these countries carry out FD programs. Beside FD, most medical/health professions education centers/departments/units are involved in curriculum planning and design, course evaluation, research, and medical programs. Usually, the medical/ health professions education centers/departments/units provide support in curriculum development and evaluation. They rarely involve in running a curriculum; however, this is not the case in Japan. Faculties in center for medical education in Japan usually emphasize on 
teaching basic clinical skills, e.g., history taking and physical examination or medical professionalism.

The main principle of carrying FD programs in these countries is to improve teaching and learning skills of trained participants in order to educate the undergraduate and postgraduate students. Apart from improving teaching and learning skills, the institutions in Japan conduct FD programs to bring changes to the whole organization. This purpose has been shared in one of the most traditional FD program in Japan, called Fuji-ken. Only those who are in a leadership position at doctor training institutions (medical schools, medical colleges, clinical training designated hospitals, and so forth) in charge of medical education can apply for Fuji-ken; therefore, it is expected that they are able to assist in organizational changes [14].

The participants being trained mainly comes from uni-professional rather than multi- or inter- ${ }^{-}$professional. They are generally the new staff, curriculum committee members, course convener, as well as clinical teachers, clinicians, and practitioners. Biomedical science teachers, on the other hand, were less-trained mainly in Singapore and Korea probably because priorities are given to the selective group such as clinical teachers who play an important part of medical education as well as the learning environment and atmosphere [15]. Studies have also shown that the majority of FD interventions were targeted on practicing clinicians instead of biomedical science educators. The lack of training among this group of educators might need to be re-looked [16].

There are various training approaches to conduct FD programs as discussed in Table 3. Workshops, seminars, and short courses are extensively used by the medical/ health professions education center/department/unit in these countries. Similar to the systematic review conducted by Steinert et al. [16], the majority of the interventions were workshops for the past 2 decades even though with the advancement of technology in teaching and learning such as massive open online course and blended learning. The use of technology for FD is still not so popular in these regions perhaps due to the IT facilities were not well-equipped (refer to Table 4, support system). Fabry and Härtl [17] also pointed out that one of the challenges for teaching and learning in many places is there is yet to have consensus on the competencies teachers need to master a sound pedagogical approach in this digitalization world. Although FD has traditionally taken place through a formal program, informal learning opportunities in authentic environments is equally important [18]. However, informal learning (such as peer learning, directed self-learning, community of practice, and on-the-job training) is still not well-received in these regions. The reasons behind this could possibly investigated in future.

The highly discussed topic among these countries is related to teaching and learning followed by assessment methods. This is not surprising as studies from other countries have shown the main focus of the interventions is on the improvement of teaching performance, teaching and learning approaches, and assessment [16]. While other countries also focus on educational leadership and educational scholarship, there is a need to increase attention in these areas. Steinert [19] highlighted that there has been an over-emphasis on instructional effectiveness and call for a more comprehensive program to include leadership and management skills, professional academic skills, and organizational development. Nevertheless, it is obvious that the countries surveyed value the benefits of FD in training future health professions educators. This can be seen in terms of the incentives provided as well as the funding to carry out FD program. Most FD programs are either fully or 
partially funded by their respective educational institutions to encourage participants to attend. Some would incentivize participants by making it mandatory as part of job requirements or giving credit points for promotion.

This form of incentives provided would definitely motivate not only the participants but also the facilitators to develop beneficial and meaningful FD programs. In addition, lack of funding no longer the main limitations in operationalizing a FD program in these four countries. The lack of support staffs, facilitators, and incentives as well as competing interests (research and/or practice obligations) have shown to be the key limiting factors in these countries. These challenges are not uncommon and have been around for many years as pointed out by Sorcinelli [20] in 2007. One of the primary challenges identified is balancing multiple roles and responsibilities such as a scholar, teacher, and clinician. Suggestion to overcome these challenges is to include coaching and mentoring in the program to support the staff which might be lacking currently.

Research in FD within these regions will require a lot of support as shown in the results. Off all the FD studies which have been published, the majority came from the United States, followed by Canada and the United Kingdom [18]. The lack of research publication in this area in Asia is apparent as most of the institutions surveyed within the four countries do not carry out research in FD [21]. However, there are multiple reasons for this. Language might be a barrier for countries where English is not their first-language. Furthermore, to carry out quality and publishable research in FD is quite challenging. The weaknesses listed by Steinert [19] for the existing research in FD are limited evaluation data, reliance on self-report data and small sample size. A possible solution highlighted by the studies is through partnership between academic institutions. Hopefully, this area will be strengthened with more collaboration and support.

\section{Limitations}

There were several limitations in the study. First, the questionnaire response rate was not very high in each country especially in Japan. This was due to challenges in recruiting the schools to respond voluntary in one country. Next, the findings from the questionnaire may not be generalizable to the entire country due to the response rate. Although questionnaire has been sent to nine countries' representatives, only institutions from the four countries responded despite several rounds of follow-up. While the results revealed the FD program in these four countries, it should be noted that the culture and policy in each country might influence the outcome of the results which was not the main discussion in this study.

\section{Conclusions}

In this study, the data collated from the surveys have highlighted a few key points towards the current growth of FD in medical education in the Asia Pacific regions. FD in medical education or health professions education has becoming more common in these regions and it is carried out to improve the teaching and learning skills of trained participants, particularly clinical teachers. While workshops and seminars are frequently used to conduct yearly FD programs in the institutions, leveraging the use of technology should be highly encouraged especially to prepare the faculty members during critical or emergency situation (such as coronavirus disease 2019). In addition, providing support for health professions educators to be involved in research related FD program should be the priority since this area has not been well-studied in these countries.

As such, regional collaboration between countries in 
APME-Net to work hand-in-hand to address key areas of interest and develop more standardized and productive FD medical education will be ideally beneficial. However, there will always be barriers to the implementation of FD across all regions [20]. Such barriers include the lack of resources, commitments, and interests at various levels individual, institution, and transnational. By addressing these key areas of interest and challenges as well as understanding the different emphasis on FD in each country will eventually facilitate a smooth and successful medical education reform in Asia.

\section{ORCID:}

Dujeepa D. Samarasekera: https://orcid.org/0000-0002-6916-6741; Shuh Shing Lee: https://orcid.org/0000-0002-6760-1340; Ardi Findyartini: https://orcid.org/0000-0002-9601-3994; Rita Mustika: https://orcid.org/0000-0001-6891-769X; Hiroshi Nishigori: https://orcid.org/0000-0002-0715-7073; Shunsuke Kimura: https://orcid.org/0000-0003-0012-1243; Young-Mee Lee: https://orcid.org/0000-0002-4685-9465

Acknowledgements: We would like to thank all schools from different regions who voluntarily took part in this research and APME-Net members for their expertise and guidance throughout all the aspects of our study.

Funding: No funding provided for this research.

Conflicts of interest: No potential conflict of interest relevant to this article was reported.

Author contributions: All authors are involved in the conception or design of the work, data collection, data analysis, and interpretation, and drafting the article, critical revision of the article, and final approval of the version to be published.

\section{References}

1. Steinert Y. Perspectives on faculty development: aiming for 6/6 by 2020: version 2. Perspect Med Educ. 2012; I(1):31-42.

2. Centra JA. Types of faculty development programs. J High Educ. 1978;49(2):151-162.

3. Sheets KJ, Schwenk TL. Faculty development for family medicine educators: an agenda for future activities. Teach Learn Med. 1990;2(3):141-148.

4. Steinert Y. Faculty development in the health professions: a focus on research and practice. Dordrecht, Netherland: Springer; 2014.

5. Steinert Y, O'Sullivan PS, Irby DM. Strengthening teachers' professional identities through faculty development. Acad Med. 2019;94(7):963-968.

6. Stes A, Min-Leliveld M, Gijbels D, van Petegem P. The impact of instructional development in higher education: the state-of-the-art of the research. Educ Res Rev. 2010;5(1):25-49.

7. Steinert Y, Mann K, Centeno A, et al. A systematic review of faculty development initiatives designed to improve teaching effectiveness in medical education: BEME guide no. 8. Med Teach. 2006;28(6):497-526.

8. Amundsen C, Wilson M. Are we asking the right questions?: a conceptual review of the educational development literature in higher education. Re Educ Res. 2012;82(1):90-126.

9. Leslie K, Baker L, Egan-Lee E, Esdaile M, Reeves S. Advancing faculty development in medical education: a systematic review. Acad Med. 2013;88(7):1038-1045.

10. Phuong TT, Cole SC, Zarestky J. A systematic literature review of faculty development for teacher educators. High Educ Res Dev. 2018;37(2):373-389.

11. Townsend J, Zorek JA, Andrieu SC, et al. Developing interprofessional education at one U.S. dental school: 
establishing a baseline and moving forward. J Dent Educ. 2018;82(5):446-453.

12. Christianson TM, Bainbridge L, Halupa C. A pilot study on interprofessional education: how prepared are faculty to teach? Prof Dev Educ. 2019;45(4):659-669.

13. Doll J, Maio A, Potthoff M. Epic failure: lessons learned from interprofessional faculty development. Perspect Med Educ. 2018;7(6):408-411.

14. Japanese Society for Medical Education. The 46th Workshop for Medical Educators. http://jsme.umin.ac.jp/ ann/jmse_an_190805_ws46.html. Accessed April 22, 2020.

15. Lo WL, Lin YG, Pan YJ, Wu YJ, Hsieh MC. Faculty development program for general medicine in Taiwan: past, present, and future. Ci Ji Yi Xue Za Zhi. 2014; 26(2):64-67.

16. Steinert Y, Mann K, Anderson B, et al. A systematic review of faculty development initiatives designed to enhance teaching effectiveness: a 10-year update: BEME guide no. 40. Med Teach. 2016;38(8):769-786.

17. Fabry G, Härtl A. Faculty development: full steam ahead! GMS J Med Educ. 2017;34(4):Doc50.

18. Webster-Wright A. Reframing professional development through understanding authentic professional learning. Rev Educ Res. 2009;79(2):702-739.

19. Steinert Y. Faculty development in the new millennium: key challenges and future directions. Med Teach. 2000; 22(1):44-50.

20. Sorcinelli MD. Faculty development: the challenge going forward. Peer Rev. 2007;9(4):4-8.

21. Karunathilake IM. Faculty development the south east Asian region-challenges and opportunities. South East Asian J Med Educ. 2017;11(2):1-2. 